\title{
MANUFACTURING AND PERFORMANCE EVALUATION OF A PROTOTYPE WOOD CHIPPING MACHINE TO PRODUCE MINI-CHIPS
}

\author{
M.A. Tawfk ${ }^{*}$ \\ M.I. El-Didamony ${ }^{* *}$
}

ABSTRACT

The oversize wood chips are existing in the conventional disc chipper production even with tuning the chipper settings which is not convenient to be used in the some applications that need to small sizes chips as biomass pellets or poultry litter for instances, hence there is an urgent need to produce mini-chips $\left(M_{C H I P S}\right)$ to become abundant for wide range of agricultural utilization within the farm. Thus, the present study aims to manufacture and evaluate the performance a local made prototype wood chipping machine by providing the conventional wood disc chipper with built-in swinging hammer mill and concave screen behind the cutting disc on the same rotating shaft using the pruning residues of mango trees to produce $M_{C H I P S}$ with high quality (uniform chips with minimum fines) and low energy requirement. The performance of the chipping machine was evaluated under operational variables including; three cutting rotational speeds of 750, 1000 and 1250 rpm corresponding to peripheral speeds of $17.66,23.55$ and $29.43 \mathrm{~m} / \mathrm{s}$, respectively, three cutting angles of $48^{\circ}, 50^{\circ}$, $54^{\circ}$ and $58^{\circ}$, three concave screen sizes of 12,16 and $20 \mathrm{~mm}$, where the hammers has the same rotational speed of the cutting disc. The machine performance was investigated taking into consideration the machine productivity, particle size distribution, and energy requirement. The results indicated that, it is recommended to use the prototype chipping machine at cutting speed of $1000 \mathrm{rpm}(23.55 \mathrm{~m} / \mathrm{s})$, cutting angle of $58^{\circ}$ and screen size of $16 \mathrm{~m}$ to obtain the best $M_{C H I P S}$ particle size distribution $\left(M_{\text {CHIPS }} \leq 3 \mathrm{~mm}=6.05 \%, M_{\text {CHIPS }}>3-8 \mathrm{~mm}=24.07 \%, M_{\text {CHIPS }}>8-12 \mathrm{~mm}=\right.$ $39.95 \%$ and $\left.M_{C H I P S}>12-16 \mathrm{~mm}=29.93 \%\right)$ to achieve regular $M_{C H I P S}$ with minimum fines at machine productivity of $1.40 \mathrm{Mg} / \mathrm{h}$ and consumed energy of $12.35 \mathrm{~kW} \cdot \mathrm{h} / \mathrm{Mg}$.

Keywords: prototype chipping machine, wood disc chipper, hammer mill, pruning residues, mini-chips, machine performance

\footnotetext{
*Assistant. Prof., Agric. Eng. Dept., Fac. of Agric., Zagazig Univ., Egypt.

${ }^{* *}$ Lecturer, Agric. Eng. Dept., Fac. of Agric., Tanta Univ., Egypt.
} 


\section{INTRODUCTION}

gricultural residues represent very serious problem in Egypt
facing the people and government economically and
environmentally. It is possible to obtain many benefits by exploiting all of these residues through some applications like animal feed, organic fertilization, animal bedding, bioenergy generation and many other usages in the farm (Bakr et al., 2016). Therefore, the concept of utilizing the biomass as a potential renewable energy resource to produce heat, electricity, and power become more interesting in last few decades (Atyia et al., 2017). Exploiting the wheat straw, rice straw, cotton stalks, corn stover, bagasse or even rice hull are very common in Egypt as biomass feedstock for generating bioenergy or even in animal feed and bedding ,but the utilization of the fruit trees pruning residues is very rear. Recently, Egyptian farms produce about 30 Mega ton annually of agricultural residues where fruit tree pruning contribute with $12.3 \%$ of total national residues (FAO, 2017). Sharkia governorate comes in the second place of the national production of mango, so the mango pruning residues is abundant but unfortunately no recent or previous attempts to be used in different purposes except firing. Simultaneously, converting the tree pruning to small chips can be promote and upgrade these solid residues in very wide range of agricultural applications; such as, animal feeding, biomass pellets or even poultry litter. Chipping process is preferable to smash the solid residues due to it produces predictable properties particles (Di Fulvio et al., 2015). Length size distribution and percentage of fines (small-size particles) are considered important quality parameters (Jensen et al., 2004), where the achieving of the right lengthsize distribution is tough challenge (Spinelli et al., 2005).The present work is focused on producing uniform small-sizes wood chips to be used different applications by the comminution of mango tree pruning using wood chipper. Chippers are comminution machines used to produce wood chips and can be divided into two types; the disc and drum chipper, where the disc chipper has simple design and higher energy efficiency than the drum chipper, despite the drum chipper has more productivity but it's insignificant. (Spinelli et al., 2013). There are many critical factors 
affecting the chipper performance and consequently the production quality such as; cutting angles, cutting speed and chips length settings (Reczulski, 2015) as well as height of knife from disc, logs moisture content, feeding rate and many others. The spout angle $(\varepsilon)$ and knife velocity can control chips geometry (Reczulski, 2016), while the cutting angles are involved: the cutting angle or the rake angle $(\gamma)$, sharpness angle $(\beta)$ and clearance angle $(\alpha)$ where the sum of the three angles is $90^{\circ}$ (Abdellah et al., 2011), as depicted in Fig.(1). The sharpness angle can be lied between $30-45^{\circ}$ (Gonçalves and Néri, 2005), while the clearance angle between 5 to $8^{\circ}$ (Gendek, A. and A. Nawrocka, 2014). It was noticed that wood chips length can be varied by using different heights of cutting knife from the disc surface in the recommended range of 18.1 to $21.1 \mathrm{~mm}$ for the knives with constant width (Hellström et al., 2009). It is very essential to operate the chipper at cutting speed not exceed $25 \mathrm{~m} / \mathrm{s}$ to avoid the too small size chips (Reczulski 2013) because the excessive cutting speed in trial to increase the machine efficiency is inappropriate (Hernandez and Jacques, 1997), also using very high or low logs moisture content can lead to produce a large amounts of the small chips and fines which declines the chips quality and gives more emission (Hartmann et al., 2006). Regarding the small-size (mini-chips) chips production, the conventional chipper can be equipped with machines provided with chips -breaker or screens to reduce the over-size chips (Facello $\boldsymbol{e t}$ al., 2013) and the screen size can affect significantly (Nati $\boldsymbol{e} t$ al., 2010). Moreover, the production of mini-chips Accordingly, the main goal of the present study is manufacturing and evaluating the performance a local made chipping machine by providing the conventional wood disc chipper with built-in swinging hammer mill with concave screen behind the cutting disc as integration system for chipping the pruning residues of mango trees to produce regular mini-chips with minimum fines (smallsize chips) to be used in wide range of agricultural applications such as, animal feeding, biomass pellets and poultry litter because the oversize chip is existing in the conventional disc chipper even with tuning the chipper settings. 


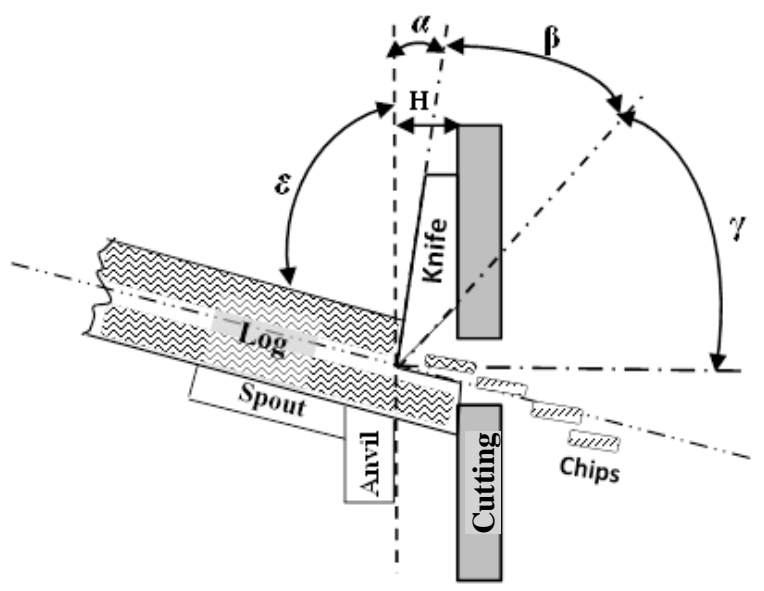

Fig. (1): The chipping angles (Abdellah et al., 2011)

\section{MATERIALS AND METHODS}

The practical experiments were carried out at Abou Hammad district, Sharkia, Egypt to evaluate the performance of a locally manufactured a prototype chipping machine including basically of a wood disc chipper equipped with a swinging hammer mill behind the cutting disc in one synergic machine to produce uniform mini-chips with less fines and power requirement.

\section{Materials}

\subsection{Wood logs characteristics}

The pruning residues of mango trees were collected from a private mango orchard at Abou Hammad district with the average moisture content range of $14 \%$. Due to the chipping of smaller logs diameters gives the chipper inferior quality chips (Krajnc and Dolšak, 2014), so the average diameter of the pruning logs selected in the range from 40 to $120 \mathrm{~mm}$.

\subsection{The prototype chipping machine specifications:}

The prototype machine consists of main frame, chipping machine (conventional wood disc chipper equipped with swinging hammer mill), transmission system and power unit, as illustrated in Fig.(2).

\subsubsection{The main Frame}

The main frame is a rectangular shape base which made of steel iron with overall length of $1495 \mathrm{~mm}$ and $500 \mathrm{~mm}$ in width with $100 \mathrm{~mm}$ in 
thickness. This frame is carrying the prototype chipping machine (disc chipper equipped with hammer mill) and electric motor. The base provided with inverted U-shaped stand constructed from iron bars. The overall dimensions of the machine stand were $515 \mathrm{~mm}$ in length, $500 \mathrm{~mm}$ for width. Electric motor base constructed of iron sheet and fixed to the base with 4 bolts with dimensions of $7 \mathrm{~mm}$ thickness, $450 \mathrm{~mm}$ length and $450 \mathrm{~mm}$ width.

\subsubsection{The prototype chipping machine}

The construction features of the prototype machine can be described as follows:

\subsubsection{Machine case}

The case of machine is the accommodation of the cutting disc and the hammer mill that constructed of cylindrical-shaped iron sheet with $5 \mathrm{~mm}$ thickness, $300 \mathrm{~mm}$ width and $750 \mathrm{~mm}$ in diameter. The volute was provided with a folded gate at the upper circumferential part to facilitate reaching to the internal components for repairing and maintenance purposes to control the logs path towards the cutting disc through the machine volute an inclined conical side chute was used as feeding duct with rectangular inlet port $(320 \times 162.5 \mathrm{~mm})$, as displayed in Fig.(2). The output port $(200 \times 300 \mathrm{~mm})$ can deliver the received $M_{C H I P S}$ from the hammer mill concave screen

\subsubsection{Cutting disc}

The cutter disc is a high rotating plate with diameter $450 \mathrm{~mm}$ provided with sharpened knives that made from iron with $20 \mathrm{~mm}$ thickness. The plate is attached strictly to a thermal hardened shaft that made of iron bar metal with dimensions of $50 \mathrm{~mm}$ diameter and $659 \mathrm{~mm}$ length and rotates throughout a two high speed bearings that fixed on the machine stand, where one end coupled to the drive pulley and the other end extended to carry both the cutting disc and the hammers simultaneously. Three cutting knives fixed on the radial direction of the disc with regular angles $\left(120^{\circ}\right)$, as shown in Fig. (3). Every knife was made from hard steel 52 carbons, with dimensions of $200 \mathrm{~mm}$ length and $70 \mathrm{~mm}$ width. 


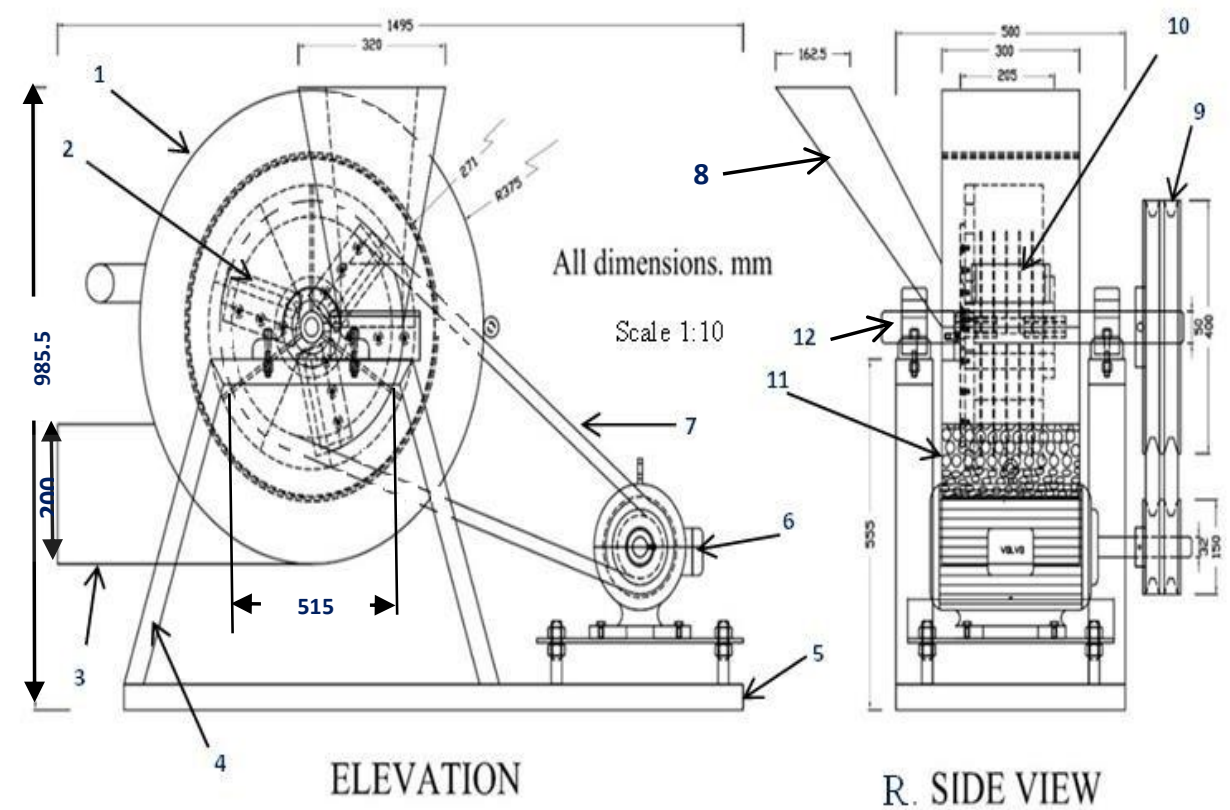

Fig.(2): The prototype chipping machine.

1- Machine case ; 2- Cutting disc; 3- Outlet port; 4- Machine stand; 5- The base; 6Electric motor; 7- Belt; 8- Input chute; 9- Pulley; 10- Hammer mill; 11-Concave screen; 12- Machine shaft

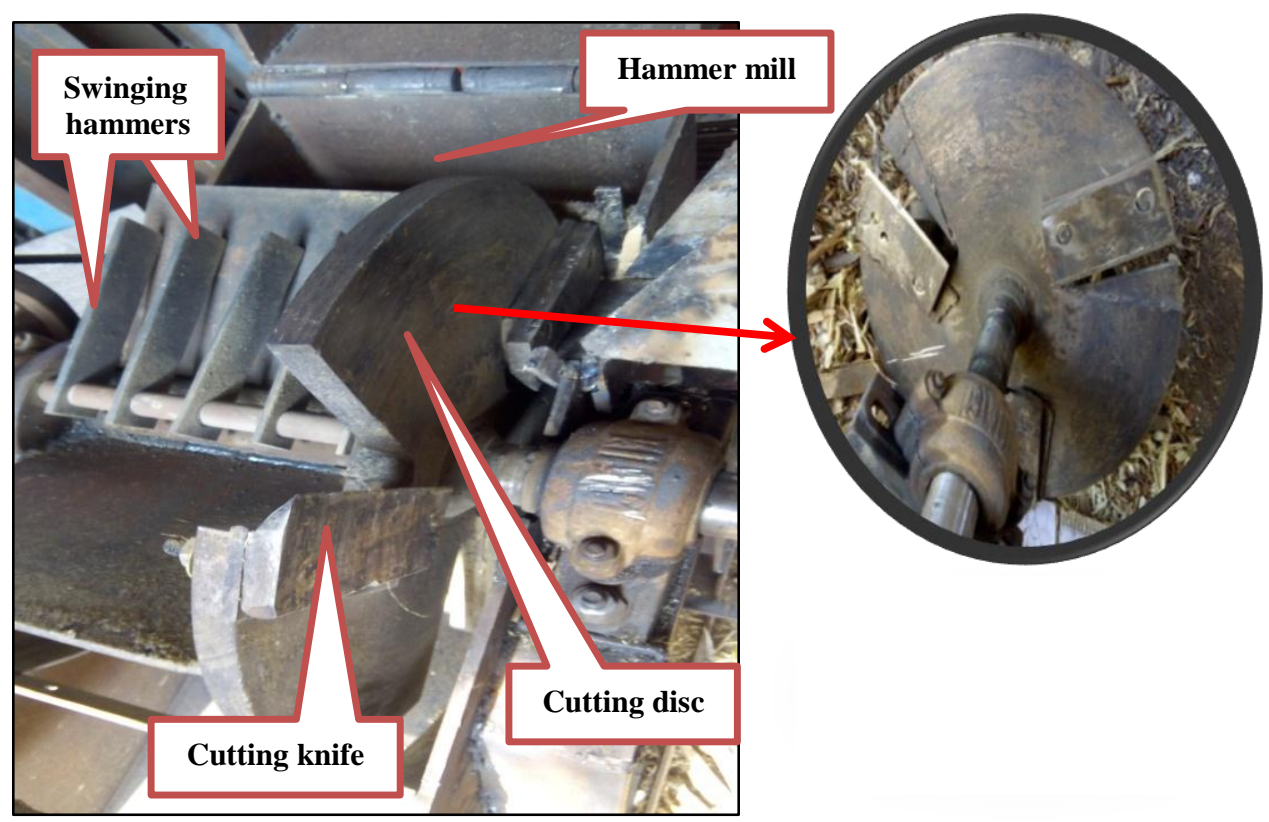

Fig.(3) : Internal components of the prototype chipping machine. 


\subsubsection{Hammer mill}

As illustrated in Fig.(3), hammer mill is fixed behind cutting disc, where it rotates by the same extended shaft of the cutting disc which is consists of three hammers groups .Each group has an iron bar with dimensions of $25 \mathrm{~mm}$ diameter, $195 \mathrm{~mm}$ length. Every bar has 5 hardened swinging hammers with total number of 15 hammers. The hammers fixed with bars that made from hard steel sheet, with dimensions of $50 \mathrm{~mm}$ width, 167 $\mathrm{mm}$ length and $3 \mathrm{~mm}$ thickness for each hammer. Accordingly, the outer diameter of the rotating hammers is $384 \mathrm{~mm}$.

\subsubsection{Transmission system and power unit}

The electric motor with total power of $11 \mathrm{~kW}$ at $1500 \mathrm{rpm}$ rotational speed was used to transmit motion to the cutting disc using the pulleys and V-belt unit by operating the drive pulley that fixed on the disc shaft. One pulley fixed on the electric motor shaft with diameter of $150 \mathrm{~mm}$ and the second pulley fixed on cutter disc shaft. To obtain four different rotational speeds for the disc ranging between 500 to $1250 \mathrm{rpm}$, four different diameters of cutting disc shaft pulley were used.

\section{Methods}

\subsection{Experiment's conditions}

In the practical experiments, the manual drop-feeding methods using logs with total weight of about $30 \mathrm{~kg} / \mathrm{min}$ as an average load that suit the small-scale operations (Spinelli and Hartsough, 2001) was used. The manufactured chipping machine performance was evaluated using a constant sharpness angle $(\beta)$ of $30^{\circ}$, spout angle $(\varepsilon)$ of $45^{\circ}$ and knife height $(H)$ of $20 \mathrm{~mm}$ above the disc surface under the following variables: -Three cutting angles $(\gamma)$ of $48^{\circ}, 50^{\circ}, 54^{\circ}$ and $58^{\circ}$, corresponding to clearance angles $(\alpha)$ of $12,10,6$ and $2^{\circ}$.

- Three cutting rotational speed of 750, 1000 and $1250 \mathrm{rpm}$ corresponding to disc/hammers peripheral speeds of $17.66,23.55$ and $29.43 \mathrm{~m} / \mathrm{s}$, respectively

- Three concave screen size (diameter) of 12, 16 and $20 \mathrm{~mm}$.

\subsection{Particle size distribution}

Regarding the size distribution of chips, the $\mathrm{M}_{\mathrm{CHIPS}}$ was classified into medium chips $(16-45 \mathrm{~mm})$, small-size $(3.15-16 \mathrm{~mm})$ and fines $(<3.15$ $\mathrm{mm}$ ) (Assirelli et al.,2013), whereas the main fraction (80\%) should be 
lied in range 3.15-16 $\mathrm{mm}$ and fines $(<3 \mathrm{~mm})$ must not exceed $5 \%$ to obtained high quality chips (Alakangas et al., 2006). Hence, four sieves of $3,8,12$ and $16 \mathrm{~mm}$ were used to classify the chip by weight into five categories of $\mathbf{M}_{\text {CHIPS }} \leq 3 \mathrm{~mm}, \mathrm{M}_{\mathrm{CHIPS}}>3-8 \mathrm{~mm}, \mathrm{M}_{\mathrm{CHIPS}}>8-12 \mathrm{~mm}, \mathrm{M}_{\mathrm{CHIPS}}$ $>12-16$ and $\mathrm{M}_{\mathrm{CHIPS}}>16 \mathrm{~mm}$.

\subsection{Measuring and Determinations}

The machine performance was evaluated with taking into consideration the following indicators:

\subsubsection{Logs moisture content}

The moisture content of mango trees pruning determined in three replicates by drying the samples in an electric oven furnace (Binder ED53).

\subsubsection{Machine productivity}

An electrical balance scale (OHAUS- U.S.A) with maximum reading of $3000 \mathrm{~g}$ and accuracy of 0.1 was used for weighting the delivered wood chips samples. Then, the chipping machine productivity was calculated using the following relation:

$$
\mathrm{M}_{\mathrm{p}}=\frac{\mathrm{W}_{\mathrm{ch}}}{\mathrm{T}} \times 3.6
$$

Where:

$\mathrm{M}_{\mathrm{p}}=$ machine productivity, $\mathrm{Mg} / \mathrm{h}$

$\mathrm{W}_{\mathrm{ch}}=$ mass of wood chips, $\mathrm{g}$

$\mathrm{T}=$ consumed time, $\mathrm{s}$

\subsubsection{Power and energy requirement}

A digital clamp meter (Super clamp meter $700 \mathrm{k}$-Japan) with an accuracy ( \pm 0.5 Ampere) was used for measuring current intensity and voltage respectively. Accordingly, the following formula was used to estimate the required power (Ibrahim, 1982):

$$
P=\frac{\sqrt{3} I \cdot V \cos \theta}{1000}
$$

Where:

$\mathrm{P}=$ Required power, $\mathrm{kW}$ 
$\mathrm{I}=$ line current strength in Amperes.

$\mathrm{V}=$ Potential strength (voltage) being equal to $380 \mathrm{~V}$.

$\cos \theta=$ power factor (being 0.7).

The specific energy requirement $(\mathrm{kW} . \mathrm{h} / \mathrm{Mg})$ was calculated by using the following equation:

The specific energy requirement $(\mathrm{kW} . \mathrm{h} / \mathrm{Mg})=\frac{\text { The required power }(\mathrm{kW})}{\text { machine productivity }(\mathrm{Mg} / \mathrm{h})} \ldots$

\section{RESULT AND DISCUSSION}

\section{1- The prototype chipping machine productivity}

Fig. (4) depicts the effect of cutting speed and cutting angle (rake angle) on the prototype disc chipper productivity under different screen sizes of the hammer mill concave. It was noticed that, the machine productivity increased consistently by increasing the cutting speed from 750 to 1250 rpm (17.66 to $29.43 \mathrm{~m} / \mathrm{s}$ ) and tends to increase very slightly with further increase of cutting speed to $1250 \mathrm{rpm}(29.43 \mathrm{~m} / \mathrm{s})$ at small screen size of $12 \mathrm{~mm}$, while this increase is clear at larger screen size of 16 and $20 \mathrm{~mm}$. The productivity increases as cutting angle increases when the other variables remained constant. Moreover, the productivity increased by increasing the concave screen size from 12 to $16 \mathrm{~mm}$, but a rapid increase was observed by using a larger screen size up to $20 \mathrm{~mm}$. Concerning the relations between cutting speed and the machine productivity, the obtained results revealed that, increasing cutting speed from 17.66 to $29.43 \mathrm{~m} / \mathrm{s}$, the highest machine productivity at cutting angle of $58^{\circ}$ and screen size of $20 \mathrm{~mm}$ was increased from 1.544 to $1.700 \mathrm{Mg} / \mathrm{h}$, but trend started to decline to reach $1.470 \mathrm{Mg} / \mathrm{h}$ at cutting speed $29.43 \mathrm{~m} / \mathrm{s}$, whilst the lowest machine productivity at cutting angle $48^{\circ}$ and screen size 12 $\mathrm{mm}$ increased very slightly from 0.658 to $.710 \mathrm{Mg} / \mathrm{h}$ and retarded to be $0.578 \mathrm{Mg} / \mathrm{h}$ at high disc speed. This is because low cutting speed produces irregular, big chips and causing more chips deformation due to the jumping phenomenon. This phenomenon means the logs feeding before the cutting disc finished chipping the previous one and this is gave large wood pieces which take more time to be shattered by the swinging hammers especially at low concave screen size. Also the excessive cutting speed means more number of cuts per wood piece in unit of time causing 
noticeable reduction in the process and a large amount of the small-size chips or even fines would be expected. The data show that the increase of cutting angle (rake angle) from 48 to $58^{\circ}$ gives more chips production under all variables of the experiment. This because the increase of cutting angle $(\gamma)$ will be companied with a decrease the clearance angle $(\alpha)$ which means the cutting process will occur before the contact of $\log$ with the cutting disc surface and the shear stress adjacent the knife edge will be parallel to the log direction and then thinner chips will be produce and consequently the productivity will increase especially at high cutting speed. Hence, the highest value of machine productivity of $1.700 \mathrm{Mg} / \mathrm{h}$ was obtained at cutting speed $1000 \mathrm{rpm}(23.55 \mathrm{~m} / \mathrm{s})$, cutting angle $55^{\circ}$ and screen size of $20 \mathrm{~mm}$, whereas the lowest value of machine productivity of $0.640 \mathrm{Mg} / \mathrm{h}$ was recorded at cutting speed $1250 \mathrm{rpm}$ $(29.43 \mathrm{~m} / \mathrm{s})$, cutting angle $48^{\circ}$ and screen size of $20 \mathrm{~mm}$.

\section{2- Mini-chips size distribution}

Fig.(5) illustrate the size distribution of the sieved $\mathrm{M}_{\mathrm{CHIPS}}$ that produced by the prototype chipping machine under different cutting speeds, cutting angles (knife rake angles) and screen sizes. The obtained results show that the large fines (25\%) was observed at lower cutting speed of 750 $\operatorname{rpm}(17.66 \mathrm{~m} / \mathrm{s})$ and cutting angle $48^{\circ}$ at small screen size of $12 \mathrm{~mm}$ and this not expected particularly for low cutting speed. This may be attributed to the increase of deformed big chips that produced due lower cutting angle and the big clearance angle which lead to remained relatively long time under the impacts of the hammer mill especially when the concave screen size is small, while at the same speed and angle, less fines was recorded at large screen size of $20 \mathrm{~mm}$. At cutting speed of $750(17.66)$ and $1000 \mathrm{rpm}(23.55 \mathrm{~m} / \mathrm{s})$ with constant screen size, by increasing cutting angle from $48^{\circ}$ to $58^{\circ}$ produces more $\mathrm{M}_{\mathrm{CHIPS}}$ (3-12 $\mathrm{mm}$ ) on the account of large chips and the fines tends to decrease, but the screen size of $16 \mathrm{~mm}$ still has less fines comparing to the screen size 12 $\mathrm{mm}$. This because the shear stress become parallel to the grain direction at high cutting angle and more thinner chips will produce but these cutting speed may give thinner chips without cracks, so despite the impacts of swinging hammers the fines from thinner chips tends decrease. 


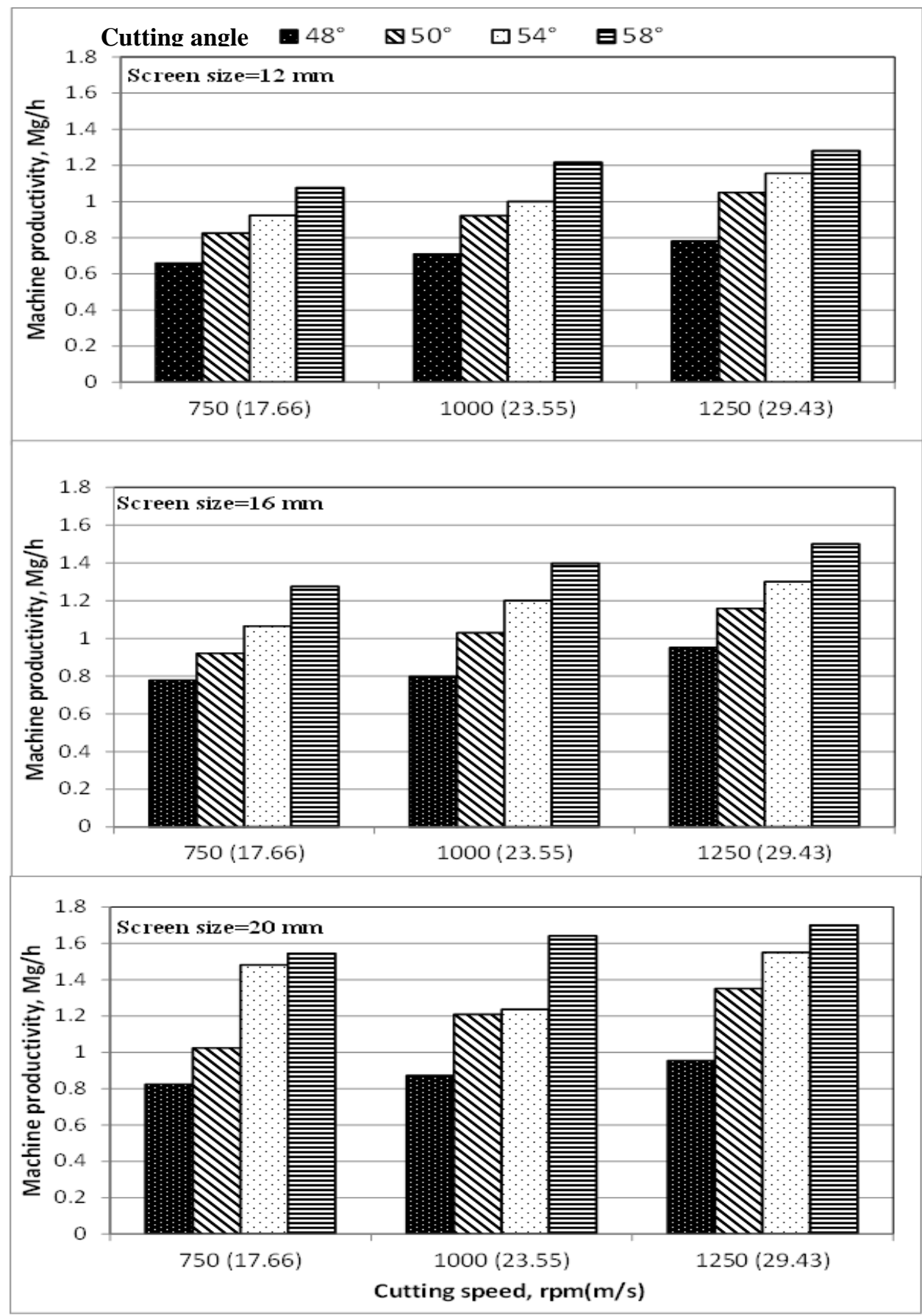

Fig.(4): Effect of cutting speed and cutting angle (rake angle) on the machine productivity at different screen sizes. 
It was observed that the increase of cutting speed up to $1250 \mathrm{rpm}$ (29.43 $\mathrm{m} / \mathrm{s}$ ) and screen size from 12 to $16 \mathrm{~mm}$ the length category of $>3-8 \mathrm{~mm}$ increased rapidly and fines decreased. This can be referred to reduction of retention time of the chips in the hammer mill especially in larger screen size of $16 \mathrm{~mm}$. Besides, the increase of cutting angle from $48^{\circ}$ to $58^{\circ}$ and screen size from 12 to $20 \mathrm{~mm}$ at the highest cutting speed of $1250 \mathrm{rpm}$ $(29.43 \mathrm{~m} / \mathrm{s})$ the fines increased rapidly in adverse behavior comparing to the other cutting speeds where the fines reached its peak at cutting angle of $58^{\circ}$, screen size of $20 \mathrm{~mm}$. This because the high cutting speed gives a very cracked short chips and simultaneously the high cutting angle accompanied with little clearance angle produces thinner wood chips and this resulting in more fines delivered from the hammer mill concave screen. In light of previous literatures, the high quality of wood $\mathrm{M}_{\mathrm{CHIPS}}$ required the fines (very small length) to be minimized to $5 \%$ or less and most of fractions (80\%) in range between $3-16 \mathrm{~mm}$, so the best average length distribution of the $\mathrm{M}_{\mathrm{CHIPS}}$ has been obtained as follows: $\mathrm{M}_{\mathrm{CHIPS}} \leq 3$ $\mathrm{mm}=6.05 \%, \mathrm{M}_{\mathrm{CHIPS}}>3-8 \mathrm{~mm}=24.07 \%, \mathrm{M}_{\mathrm{CHIPS}}>8-12 \mathrm{~mm}=39.95 \%$ and $\mathrm{M}_{\mathrm{CHIPS}}>12-16 \mathrm{~mm}=29.93 \%$, at cutting speed of $1000 \mathrm{rpm}(23.55$ $\mathrm{m} / \mathrm{s}$ ), cutting angle of $58^{\circ}$ and screen size $16 \mathrm{~mm}$, as shown in Fig.(6).

\section{3- Energy requirement}

The effect of cutting speed and cutting angle on the consumed energy that during the chipping process of mango trees pruning using different screen sizes for the hammer mill concave is illustrated in Fig.(7). At constant cutting angle, the obtained data indicated that the increase of cutting speed from 750 to $1250 \mathrm{rpm}$ ( 17.66 to $23.55 \mathrm{~m} / \mathrm{s}$ ) at smaller screen size of $12 \mathrm{~mm}$, the energy requirement is almost quasi-steady value but it tends to increase at high cutting speed of $1250 \mathrm{rpm}(29.43 \mathrm{~m} / \mathrm{s})$. At larger screen size of 16 and $20 \mathrm{~mm}$ this behavior is different where the consumed energy decreased by increasing the cutting speed from 17.66 to $23.55 \mathrm{~m} / \mathrm{s}$ due to the increase that occurred in machine productivity is higher than increase in consumed power by the cutting disc and hammers, but any further increase in cutting speed the energy requirement will increase due to the increase of friction between the knife and logs and thus cutting force will increase. 


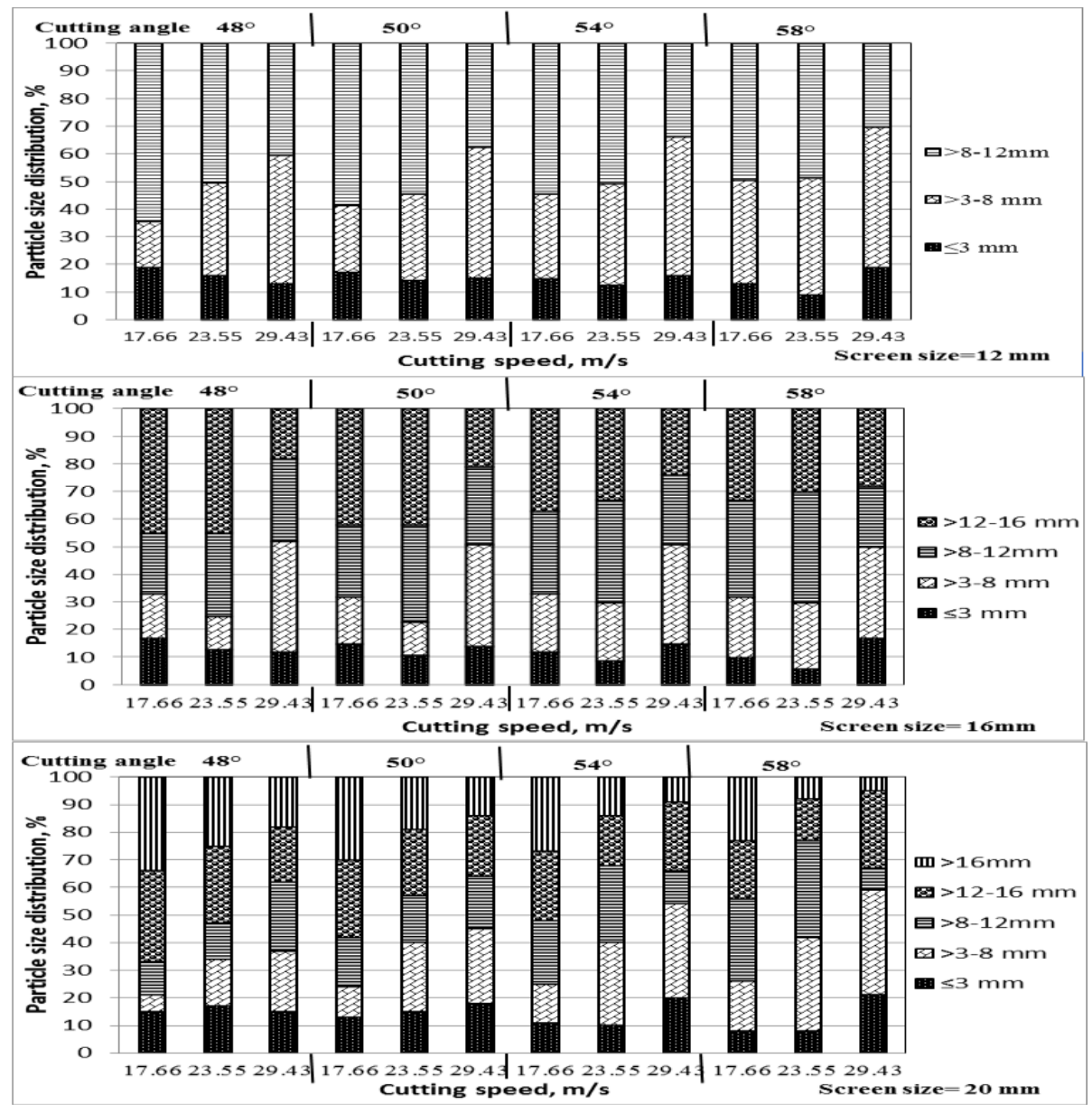

Fig.(5): Effect of cutting speed and cutting angle on particle length distribution of $\mathrm{M}_{\mathrm{CHIPS}}$ at different screen sizes.

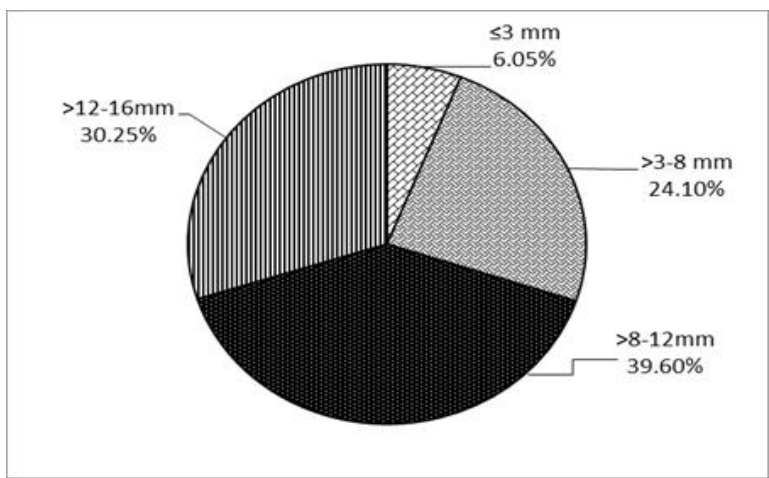

Fig.(6): The best particle length distribution for $M_{C H I P S}$ at cutting speed $23.55 \mathrm{~m} / \mathrm{s}$, cutting angle $58^{\circ}$ and screen size $16 \mathrm{~mm}$. 


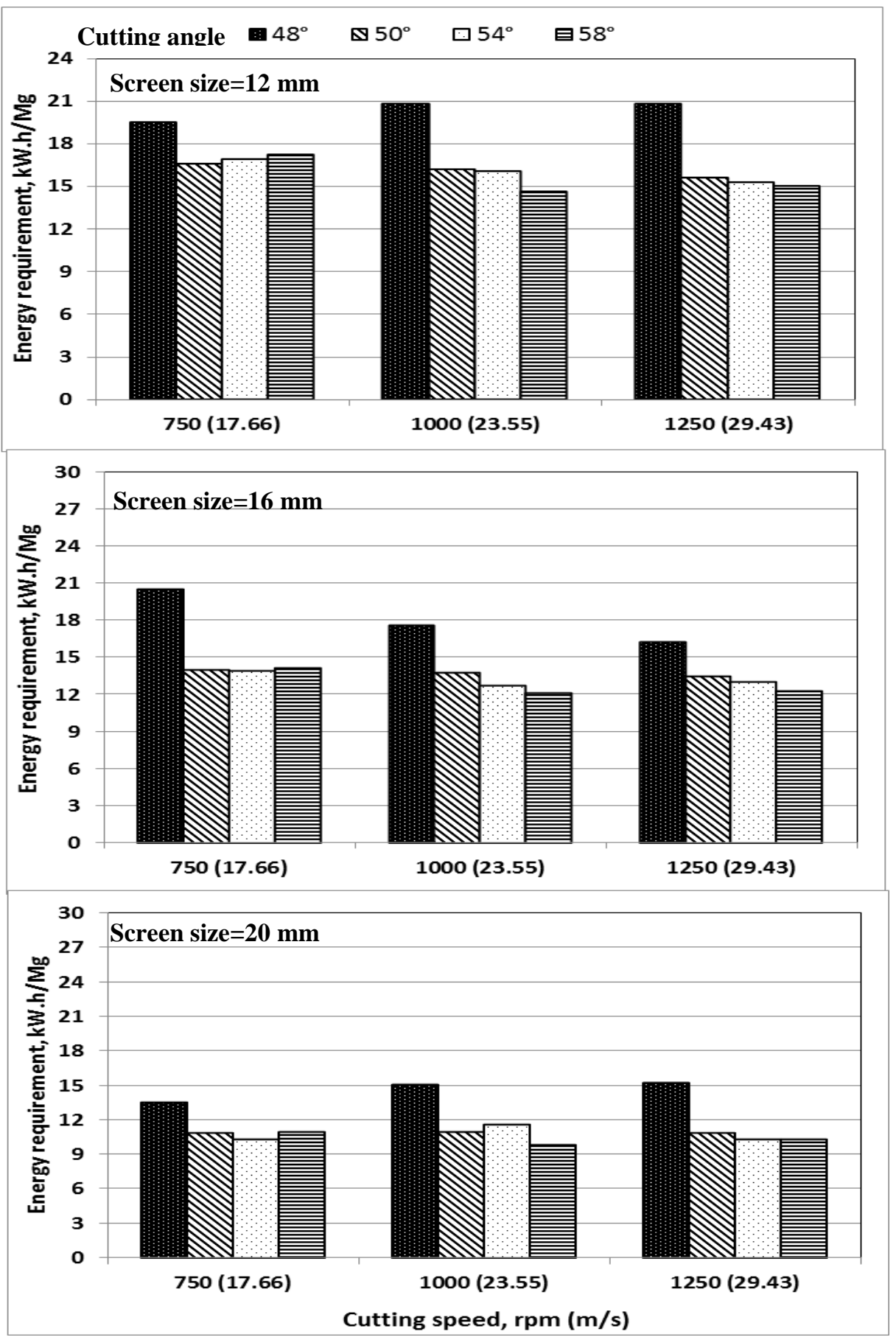

Fig. (7): Effect of cutting speed and cutting angle (rake angle) on the energy requirement for chipping process at different screen sizes. 
As general trend, increasing the concave screen size from 12 to $16 \mathrm{~mm}$ will decrease the energy requirement remarkably throughout the chipping process when the other variables remained constant. Additionally, the cutting angle affect greatly on the energy requirement for wood chipping process. On one hand, the results indicated that the increase of cutting angle $(\gamma)$ from $48^{\circ}$ to $54^{\circ}$ at lower cutting speed of $750 \mathrm{rpm}(17.66 \mathrm{~m} / \mathrm{s})$, the energy requirement decreased gradually, but adverse trend was occurred using the highest angle of $58^{\circ}$. On the other hand, the increase of cutting angle from $48^{\circ}$ to $54^{\circ}$ at higher cutting speeds of 1000 and 1250 $\mathrm{rpm}(23.55$ and $29.43 \mathrm{~m} / \mathrm{s})$, the energy requirement decreased slightly and tends to remained constant at higher cutting angle of $58^{\circ}$. This because the high cutting angle and speed causing a very high friction between the knife and logs which means more cracks in the chips after that the hammer mill consume less power, simultaneously the low cutting angle means high clearance angle which produces thicker chips and the consumed power by the hammer mill will increase to crush the chips. Hence, there is no doubt that the hammer mill affects the power consumption and consequently the specific energy requirement. Accordingly, the lowest value of specific energy requirement of 9.51 $\mathrm{kW} . \mathrm{h} / \mathrm{Mg}$ was obtained at cutting speed of $1000 \mathrm{rpm}(23.55 \mathrm{~m} / \mathrm{s})$,cutting angle of $58^{\circ}$ and screen size of $20 \mathrm{~mm}$, while the highest value of specific energy requirement of $25.35 \mathrm{~kW} . \mathrm{h} / \mathrm{Mg}$ was recorded at cutting speed of $1250 \mathrm{rpm}(29.43 \mathrm{~m} / \mathrm{s})$, cutting angle of $48^{\circ}$ and screen size of $12 \mathrm{~mm}$. From previous discussion, it was found that, the corresponding energy requirement to the best $\mathrm{M}_{\mathrm{CHIPS}}$ particle size distribution of 12.35 $\mathrm{kW} . \mathrm{h} / \mathrm{Mg}$ was recorded cutting speed of $1000 \mathrm{rpm}(23.55 \mathrm{~m} / \mathrm{s})$, cutting angle of $58^{\circ}$ and screen size of $16 \mathrm{~mm}$ at machine productivity of 1.40 $\mathrm{Mg} / \mathrm{h}$. As general note, the machine can produce more productivity with less energy requirement but the excessive fines will be existed.

\section{CONCLUSION}

According to the obtained results, it can be concluded that the optimum conditions for operating the prototype chipping machine to produce regular wood mini-chips ( $\mathrm{M}_{\mathrm{CHIPS}}$ ) with minimum fines (small-sizes chips) are the cutting speed of $1000 \mathrm{rpm}(23.55 \mathrm{~m} / \mathrm{s})$, cutting angle of $58^{\circ}$ and screen size of $16 \mathrm{~m}$ to obtain the best $\mathrm{M}_{\mathrm{CHIPS}}$ particle size distribution 
$\left(\mathrm{M}_{\mathrm{CHIPS}} \leq 3 \mathrm{~mm}=6.05 \%, \mathrm{M}_{\mathrm{CHIPS}}>3-8 \mathrm{~mm}=24.07 \%, \mathrm{M}_{\mathrm{CHIPS}}>8-12 \mathrm{~mm}=\right.$ $39.95 \%$ and $\mathrm{M}_{\mathrm{CHIPS}}>12-16 \mathrm{~mm}=29.93 \%$ ) at machine productivity of 1.40 $\mathrm{Mg} / \mathrm{h}$ and energy requirement of about $12.35 \mathrm{~kW} . \mathrm{h} / \mathrm{Mg}$.

\section{REFERENCES}

Abdallah, R., S. Auchet and P.J. Méausoone (2011). Experimental study about the effects of disc chipper settings on the distribution of wood chip size. Biomass and Bioenergy, 35(2): 843-852.

Alakangas, E., J. Valtanen and J. E. Levlin (2006). CEN technical specification for solid biofuels-Fuel specification and classes. Biomass and Bioenergy, 30(11): 908-914.

Assirelli, A., V. Civitarese, R. Fanigliulo, L. Pari, D. Pochi, E. Santangelo and R. Spinelli (2013). Effect of piece size and tree part on chipper performance. Biomass and Bioenergy, 54: 77-82.

Atiya, E. A., M.M. Morad, M.A. Tawfik and K.I. Wasfy (2017). Fabricating and performance evaluating of an experimental prototype of downdraft biomass gasifier. Zagazig J. Agric. Eng., 44 (2):727-740.

Bakr, M.M.A., M.A. El-Shazly, M.A. Tawfik and Y.S. Abdellah (2016).Study on some factors affecting the manufacturing of cattle feed pellets. Zagazig J. Agric. Eng., 43 (6A):2177-3195.

Di Fulvio, F., G. Eriksson, and D. Bergström (2015). Effects of wood properties and chipping length on the operational efficiency of a 30 $\mathrm{kW}$ electric disc chipper. Croatian Journal of Forest Engineering, 36(1): 85-100.

Facello, A., E. Cavallo, N. Magagnotti, G. Paletto and R. Spinelli, (2013). The effect of chipper cut length on wood fuel processing performance. Fuel Proces. Technol., 116:228-233.

FAO (2017). BEFS Assessment for Egypt: Sustainable bioenergy options from crop and livestock residues, Rome - Italy. Working paper: ISBN 978-92-5-109587-4.

Gendek, A. and A. Nawrocka (2014). Effect of chipper knives sharpening on the forest chips quality. Annals of Warsaw 
University of Life Sciences-SGGW. Agriculture, (64 Agric. Forest Eng.).

Gonçalves, R. and A. C. Néri (2005).Orthogonal cutting forces in juvenile and mature pinus taeda wood. Sci. Agric. (Piracicaba, Braz.), 62(4):310-318.

Hartmann, H., T. Bohm, P.D. Jensen, M. Temmerman, F. Rabier and M. Gloser (2006) Methods for size classification of wood chips. Biomass and Bioenergy, 30:944-953.

Hellström, L.M., P. Isaksson, P.A. Gradin and K. Eriksson (2009). An analytical and numerical study of some aspects of the wood chipping process. Nordic Pulp and Paper Res. J., 24(2): 225-230.

Ibrahim, M. K. (1982). Wet milling of wheat grain. M. Sc. Thesis, Faculty of Agric., Mansoura Univ., Egypt.

Jensen, P., J. Mattson, P. Kofman and A. Klausner (2004). Tendency of wood fuels from whole trees, logging residues and roundwood to bridge over openings. Biomass and Bioenergy, 26(2): 107-113.

Krajnc, M. and B. Dolšak (2014). The influence of drum chipper configuration on the quality of wood chips. Biomass and Bioenergy, 64: 133-139.

Nati C., R. Spinelli and P.G. Fabbri (2010).Wood chips size distribution in relation to blade wear and screen use. Biomass and Bioenergy, 34:583-587

Reczulski, M. ( 2013). Effect of disc chipper design parameters and physical properties of wood on chips thickness. Polish Paper Review 69(7): 344-350.

Reczulski, M. (2015).Aanalysis of the construction and operation of system wood chipping and transfer chips. Wood Res., 60(40): 671678.

Reczulski, M. (2016). The system wood chipping in disc chipperproblems of uniformity of chips length. Wood Res., 61(3):433-442.

Spinelli, R. and B. Hartsough (2001). A survey of Italian chipping operations. Biomass and Bioenergy, 21:433-444. 
Spinelli, R., B. Hartsough and N. Magagnotti (2005).Testing mobile chippers for chip size distribution. International Journal of Forest Engineering, 16: 29-36.

Spinelli, R., E. Cavallo, L. Eliasson, A. Facello (2013). Comparing the efficiency of drum and disc chippers, Silva Fennica, 47 (2): 11p https://doi.org/10.14214/sf.930.

\section{الملخص العربي}

تصنيع وتقييم أداء نموذج أولي لآلة تقطيع الأخشاب لإنتاج الرقائق المصغرة

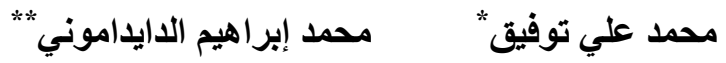

بإستخدام آلة تقطيع الأخثاب القرصية التقليدية فإن الأحجام الكبيرة لرقائق الخشب تظل حاضرة

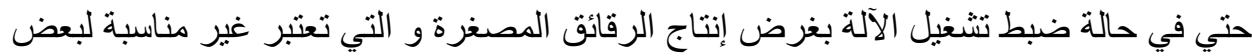
التطبيقات و التي تحتاج إلي أحجام صغيرة من هذة الرقائق مثل مصبعات الكتلة الحيوية أو حتي

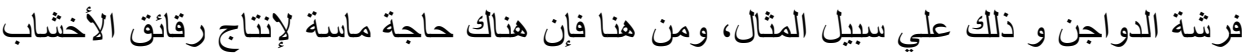

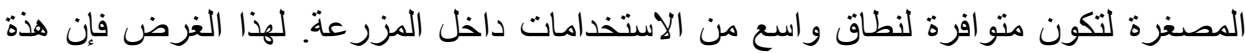

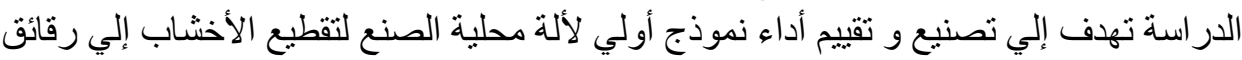
من خلال تزويد قرص التقطيع التقليدي بمجرشة ذات مطارق متأرجحة خلف القرص مباثرة

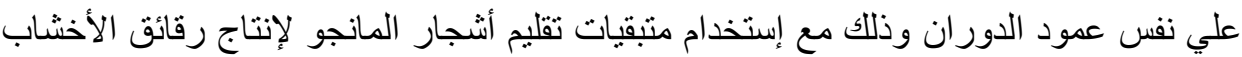
المصغرة بأعلي جودة (رقائق منتظمة الشكل و أقل فاقد من الرقائق المسحوقة) وبأقل طاقة

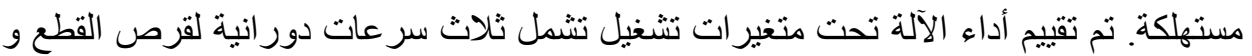

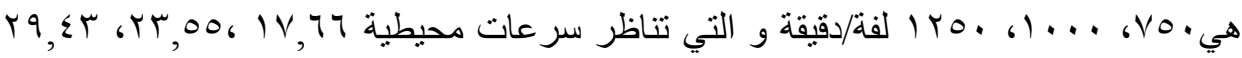

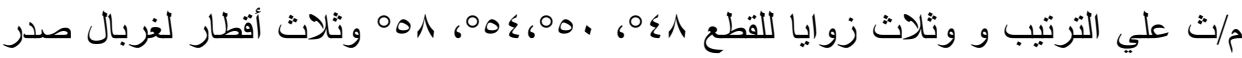

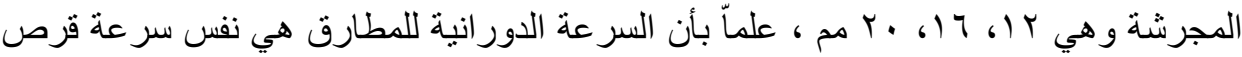

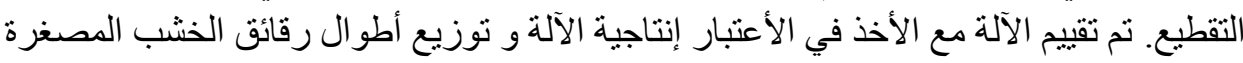

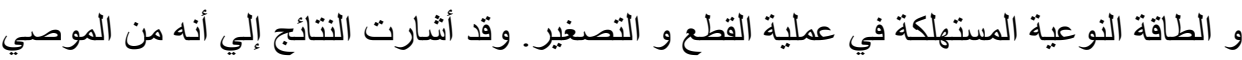
به إستخدام الآلة عند سرعة دور انية لقرص التقطيع مقدار ها . ... (1 لفة/دقيقة (

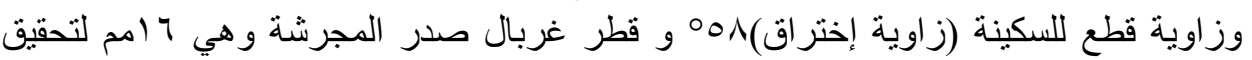

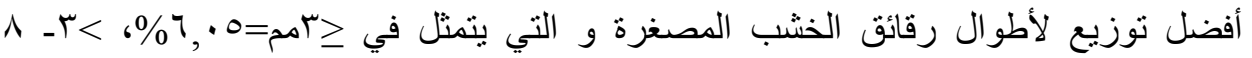

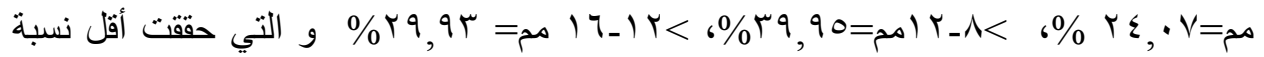

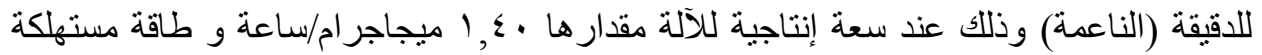

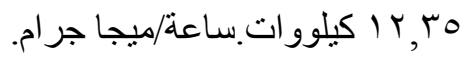

" أستاذ مساعد الهندسة الزراعية ـ كلية الزراعة ـ جامعة الزقازيق - مصرة.

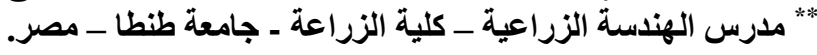

